\title{
Leaching of Minerals in Degari Coal
}

\author{
Mohammad Shakirullah, Imtiaz Ahmad, Mohammad Arsala Khan, \\ Mohammad Ishaq, Habib ur Rehman, and Uzma Khan
}

Department of Chemistry, University of Peshawar, N.W.F.P, 25120, Pakistan

Contact: Phone: +92-091-9216652,E-mail: patwar2001@yahoo.co.in

\begin{abstract}
This paper reports the demineralization of coal with EDTA, citric acid, $\mathrm{HCl}, \mathrm{HNO}_{3}$, acid mixture and $\mathrm{CH}_{3} \mathrm{COONH}_{4}$. The residual coal from each treatment was analyzed using Scanning Electron Microscopy. All the micrographs are bright field and reveal several features correspond to the mineral grains comprised of lithophiles like aluminum, potassium, and sodium; sidrophiles like iron and chalcophiles like copper and germanium. The absence of some morphological features correspond to inorganic elements in residual samples confirms demineralization. It is evident from the results that amongst the leachants used; acid mixture and EDTA have caused significant removal of mineral phases.
\end{abstract}

Keywords: Coal; Minerals; Leaching; Particle Morphology

\section{INTRODUCTION}

Fossil energy, particularly derived from coal, has been investigated from many directions. Many environmentalists see coal as inherently dirty. Coal minerals are objectionable due to process as well as environmental problems. Coal minerals may be epigenetic and syngentic. Both constitute the inorganic part of the coal and if their concentration exceeds certain levels, they are considered unwanted because of no role in combustion of coal. Minerals are desired to certain levels due to catalytic effects in gasification and liquefaction [1-3]. Concerted efforts are needed to reduce the ash forming inorganic elements and to develop clean methods of using coal. Demineralization prior to utilization is an effective way to ensure environmentally friendly combustion of coal and to compel the user to use coal for domestic as well as commercial power generation.

Many techniques are in line for demineralization of coal [4-6].However, all these treatments are tedious, obnoxious and costly. Introduction of less time consuming and cost effective techniques is the need of the day. New techniques are being viewed for removal of ash forming inorganic elements from coal [7-8]. EDTA [9], citric acid [10], 
some lixiviants [11] $, \mathrm{HCl}, \mathrm{HNO}_{3}, \mathrm{NaOH} \& \mathrm{H}_{2} \mathrm{O}_{2}$ [12] and forced leaching using water, citrate, oxalate, EDTA \& carbonate solutions are in use [9].

Various analytical protocols have been used in the past for mineral mater identification [13-17]. Atomic absorption spectroscopy, x-ray diffraction, energy dispersive scattering and inductively coupled plasma mass spectrometry (ICP-MS), FTIR Imaging Direct-Current/Arc Optical Emission Spectrometric Analysis, LTA, XRD, FT-IR, and SEM-EDX , Fourier transform infrared reflection-absorption spectroscopy (IRRAS), Mid-Infrared Evanescent Wave Sensors, FT-Raman Spectroscopy techniques, X-ray photoelectron spectroscopy (ESCA) are enjoying popularity. Scanning electron microscopy is gaining importance during recent years for minerals identification [1822].

The present paper demonstrates the use of scanning electron microscopic technique to evaluate the ability of some leachants in demineralizing the coal understudy.

\section{MATERIALS AND METHODS}

\section{Preparation of Coal Sample}

The run of mine coal sample was obtained from Degari coal mines through Pakistan Mineral Development Corporation, crushed and ground in a pestle and mortar, screened through $250 \mu \mathrm{m}$ sieves using a sieve shaker. The definite sized coal sample was dried in a vacuum oven at $70{ }^{\circ} \mathrm{C}$ for one hour and cooled in a dessiccator. The proximate and ultimate analysis of the coal understudy is provided in Table 1.

Table 1. Proximate analysis of coal used.

\section{Parameter}

Moisture

Volatile Matter

Ash

Fixed Carbon

Total Sulfur

Sulfatic Sulfur

Pyretic Sulfur

Organic Sulfur

Chlorine

\section{Level (\%)}

\section{2}

34.77

11.18

46.85

1.2

0.59

0.01

0.6

0.55 


\section{Extraction Procedure}

Five grams portion of coal sample understudy was extracted separately with EDTA, buffered ETDA, citric acid, $\mathrm{HCl}, \mathrm{HNO}_{3}$, acid mixture made of $\mathrm{H}_{2} \mathrm{O}, \mathrm{HNO}_{3}, \mathrm{HCl}$ and HF (molar ratio of 10:5:1:1) and ammonium acetate. The specified amount of coal was slurried in $50 \mathrm{~cm}^{3}$ of extracting solution in a beaker. A Teflon coated magnetic stirring bar was also immersed. The beaker was placed on a water bath and the whole assembly was placed on a magnetic stirrer. The contents were stirred for time duration of 5 hours at $50{ }^{\circ} \mathrm{C}$. The temperature was maintained throughout the extraction process by addition of hot water into the water bath. After being contacted for the specified duration of time, the slurry was filtered using What man filter paper (No. 542) to remove the capture solution. The residual coal was washed exhaustively with copious amount of hot distilled water, dried in vaccum oven at $70{ }^{\circ} \mathrm{C}$ till constant mass.

\section{SEM Analysis}

SEM micrographs of the virgin and residual coal samples obtained by Scanning Electron Microscope (SEM) Model JSM 5910 from JEOL Company in Japan. Each of the samples was mounted on disc and coated with gold.

\section{RESULTS AND DISCUSSION}

The mineralogy of coal is dependent upon the processes that have occurred in the source areas, during transport and deposition and during post-depositional early diagenesis. The variation in mineral contents of different coals is due to the different extents of some or all of these factors. Coal understudy has been found to have high ash content and in turn highly contaminated by inorganic elements [23].An attempt was made to demineralize it with some leachants under different extraction conditions.

SEM micrographs of the virgin and variously leached samples are provided in Figs. 1-9. Fig.1 represents the SEM image of the virgin coal. It can be seen a bulk microstructure which in turn is composed of a homogeneously distributed network comprised of small fistulous and filamentous crystallites showing minerals. In the matrix, luminous as well as non luminous features can be seen. These features indicate the presence of minerals distributed in the organic matrix and as surface coverage. Many fissures, cleats, cracks and veins can also be seen. The bright luminosity is due to the presence of lithophiles like aluminum, potassium, sodium \& sidrophiles like iron and the dark luminosity is mainly due to the presence of chalcophiles [24]. Etiched pits, layers, some islands and hills \& valleys can also be seen randomly distributed though out the micrograph. These might be resulted from the calcinations of dolomite and calcites or their assemblages due to the thermal shock during metamorphism. Some discrete and coherent crystals (framboids, and euhedral) of irregular shapes represent the presence of iron [20-22]. Veins correspond to iron oxide can also be seen. It is inferred that the coal under study contains large proportions of silica, calcium carbonate, and dolomite, as well 
as some proportions of elements such as aluminum, iron, and potassium that proved to be in agreement with the work of previous researchers [23].

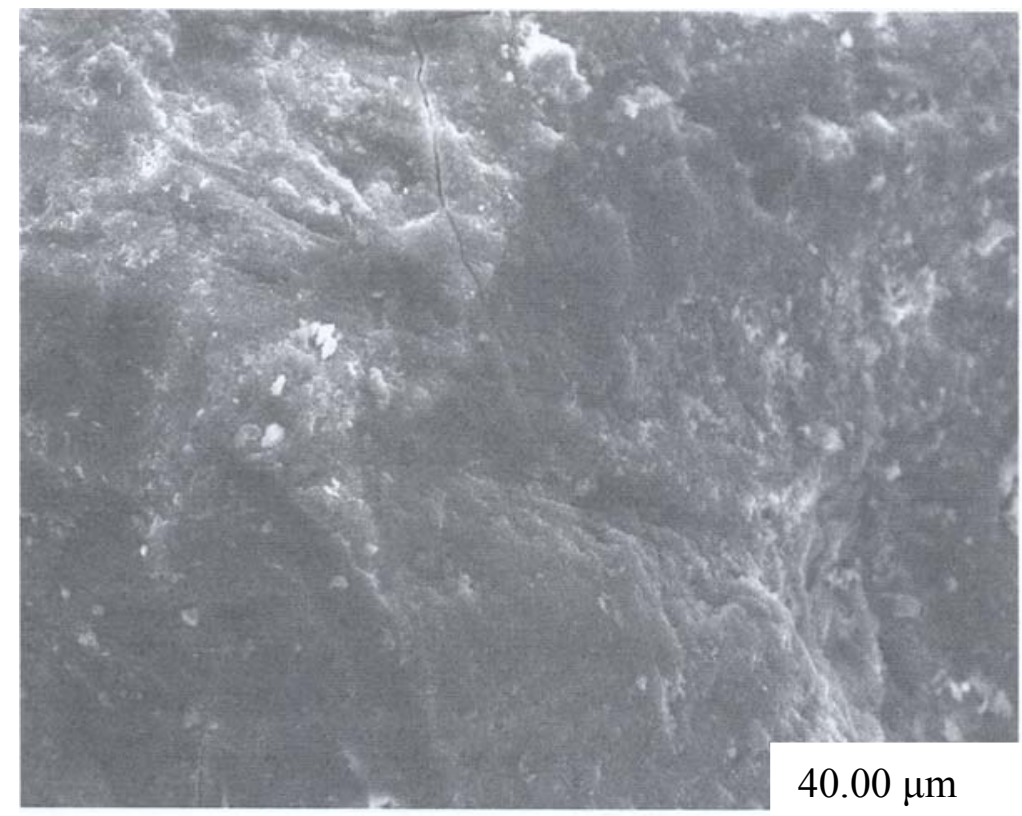

Fig. 1- SEM micrograph of virgin coal

In order to enhance channeling for effective access of the leachant, the same coal was carbonized. The SEM micrograph is provided in Fig. 2. It can be seen a very large channel almost drilled in to the matrix due to catastrophic effect of carbonization temperature. Some rounded vesicles along the channel are dominant. These bright rounded formation might be nucleated minerals resulted from high temperature treatment.

An attempt was made to remove the mineral inclusions and to enrich the coal in useable carbon. Leaching was performed with a chelating agent (EDTA) and the mineralogical study of the residual coal was done. The SEM picture is provided in Fig. 3. Numerous aggregated particles can be seen. The porosity has been increased and provides strong evidence that significant amounts of inorganic elements are being removed. However, the surface coverage is still bright and luminous indicating the presence of mineral phases. An attempt was made to exacerbate and stimulate the leaching with EDTA and buffered EDTA. The micrograph of the residue from this treatment is provided in Fig. 4. It can be seen that this leachant did little harm to the surface and the surface is as intact as in the case of virgin coal. Some minute fissures and cracks, however, are evident. The surface is bright and mostly protruded. Some islands can also be seen. The micrograph reveals that the leaching has undergone poorly. The reason might be some of the dolomitic mineral phases have gotten dissolved at the selected $\mathrm{pH}$ and have redeposited on the surface instead of their extraction. 


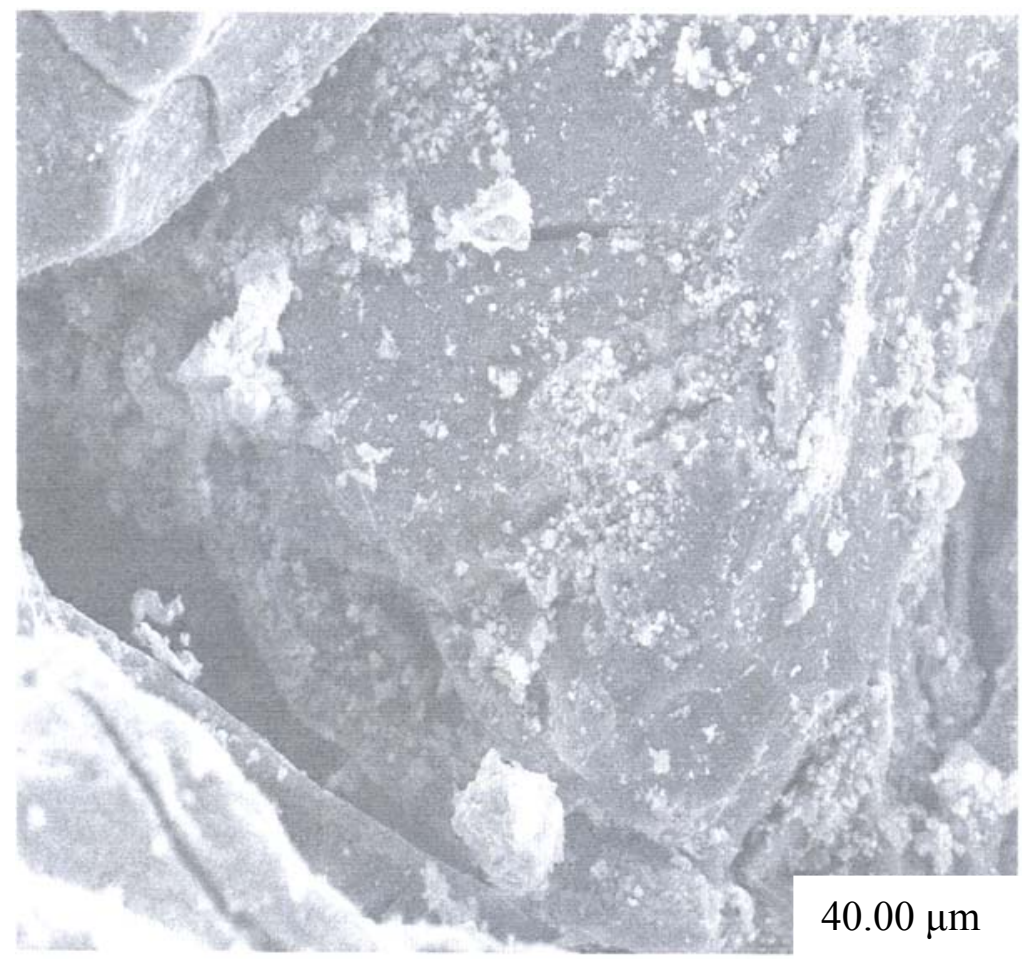

Fig. 2- SEM micrograph of carbonized coal

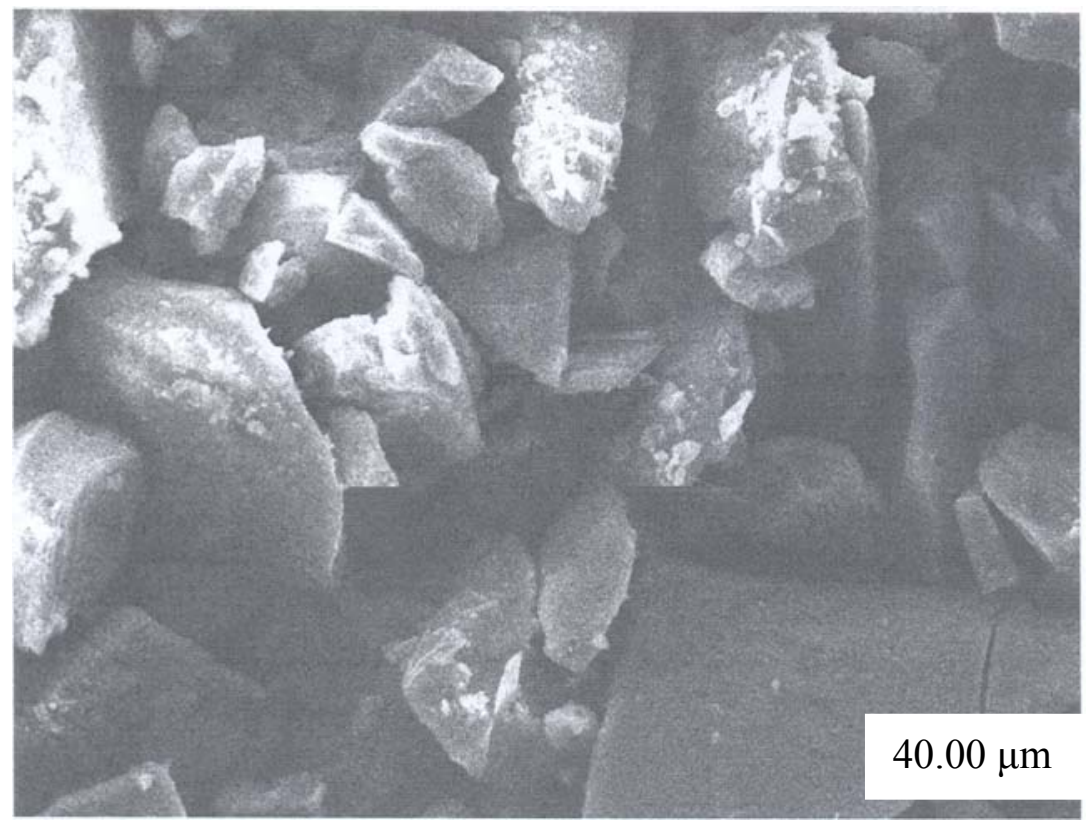

Fig. 3- SEM micrograph of EDTA leached residual coal 


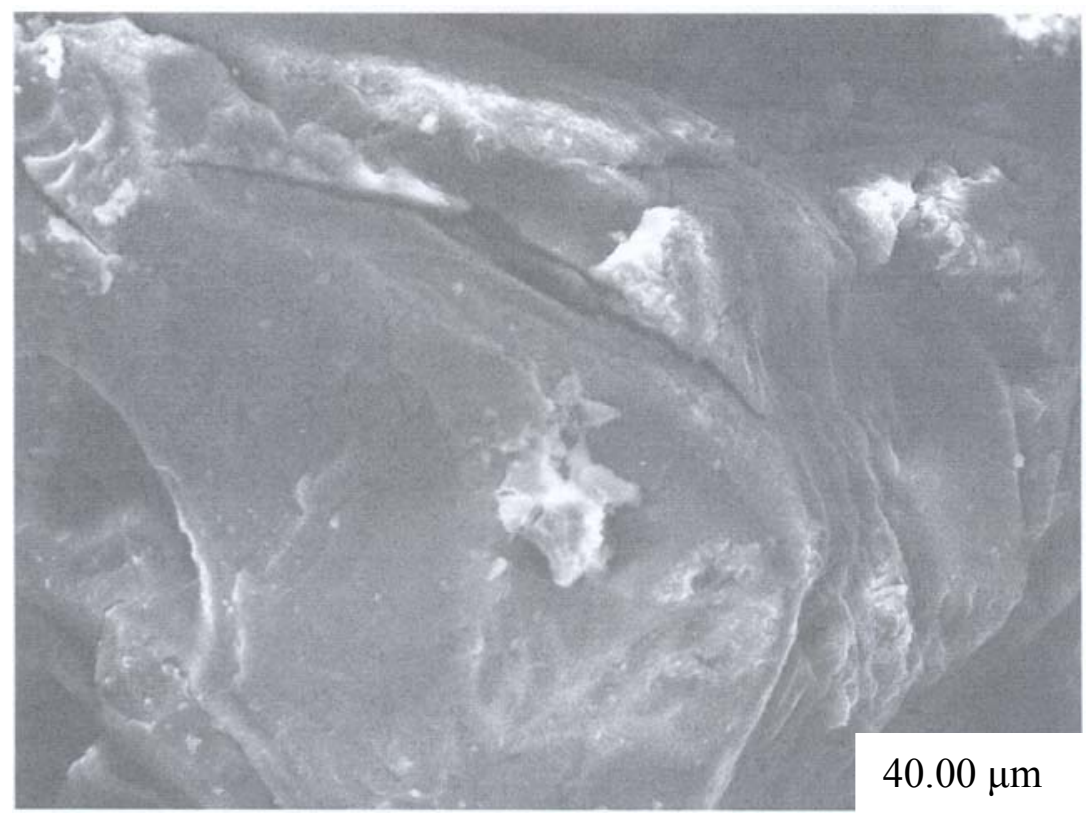

Fig. 4- SEM micrograph of buffered EDTA leached residual coal

Leaching was also performed with citric acid. The SEM image or the residual coal from this treatment is provided in Fig. 5. It can be seen that this leachant caused morphological changes in the particle and did enormous harm to the surface by leaching some of the inorganic elements. By comparing the micrograph with the one displayed in Fig. 3, one can suggest that EDTA has caused effective removal of inorganic phases than this leachant. However, this leachant seems to be more effective than the buffered EDTA (Fig. 4) in demineralizing the coal under study.

SEM micrograph of the residual coal leached with acid mixture is displayed in Fig. 6. It can be seen enormous disintegration of the mineral part of the coal as envisaged from the dominant dark organic part. However, some catastrophes are numerous. These can be removed if the coal under study is kept in contact with the leachant for longer contact time followed by washing. The micrograph upon comparing with the aforementioned images, established its importance for the removal of inorganic phases.

An attempt was also made to study the effectiveness of $\mathrm{HCl}$ as leachant. The micrograph of the residual coal from this treatment is provided in Fig. 7. The surface seems to be intact as in case of original coal. The surface coverage with grains is also evident which confirms poor demineralization with this leachant. 


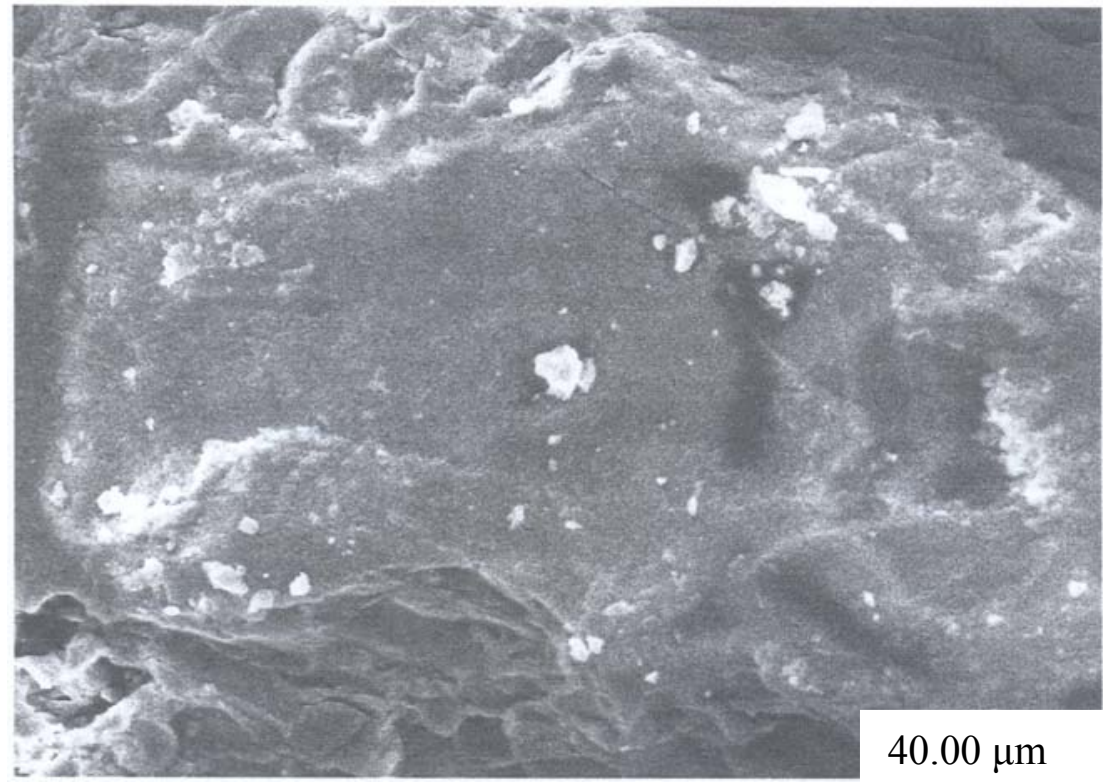

Fig. 5- SEM micrograph of citric acid leached residual coal

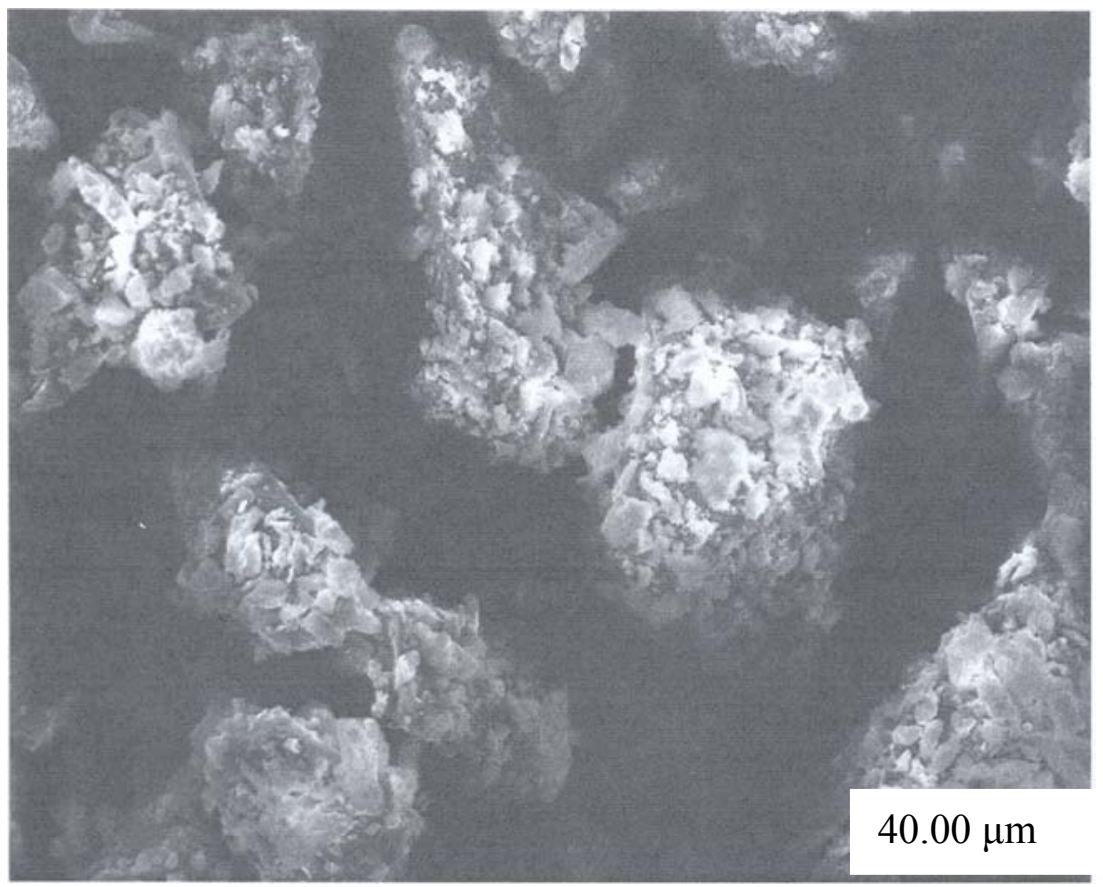

Fig. 6- SEM micrograph of acid mixture leached residual coal

Leaching was also performed with $\mathrm{HNO}_{3}$ as leachant. The SEM micrograph displaying several features like generation of some fissures, kerfs, and vesicles (Fig. 8). 
This is evident from demineralization of some of the inorganic elements like pyrites. Mineral acids have been proved as effective leachant for pyrite removal [25-26].

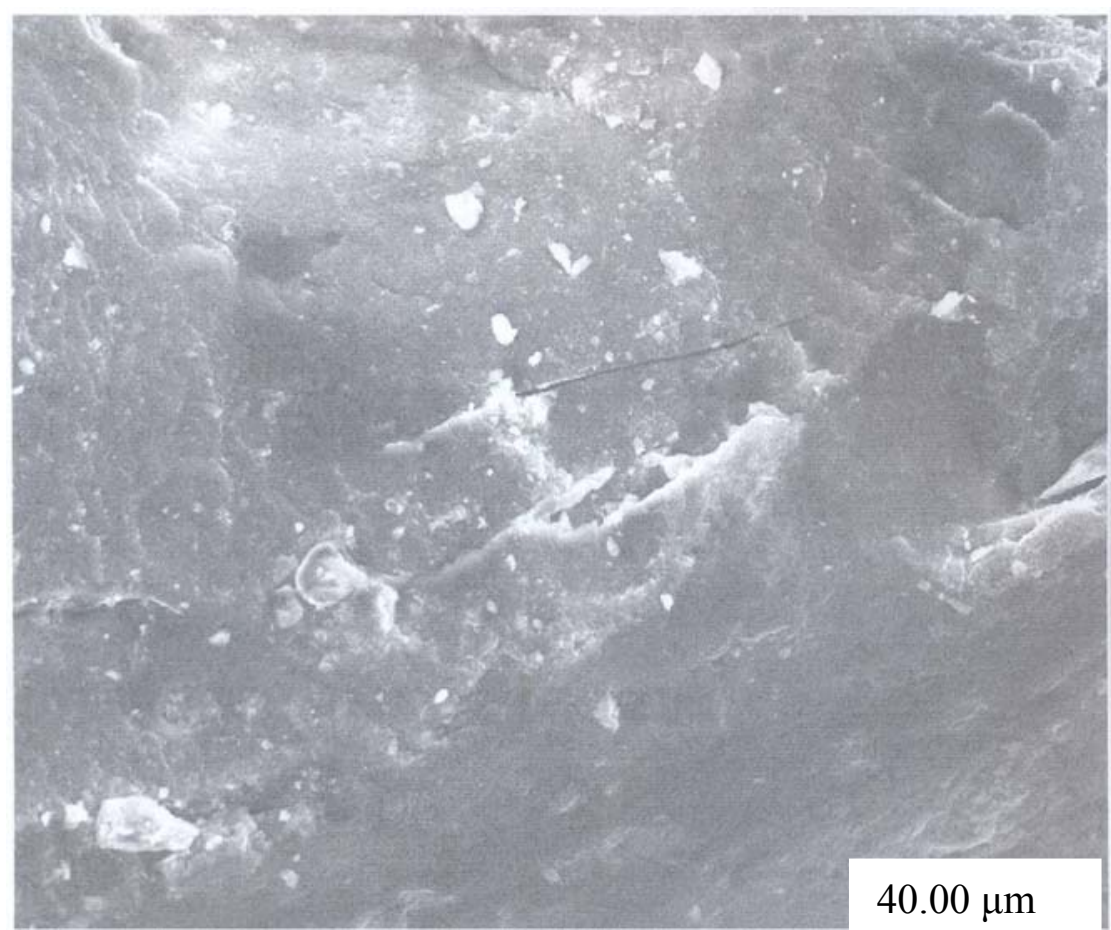

Fig. 7- SEM micrograph of $\mathrm{HCl}$ leached residual coal

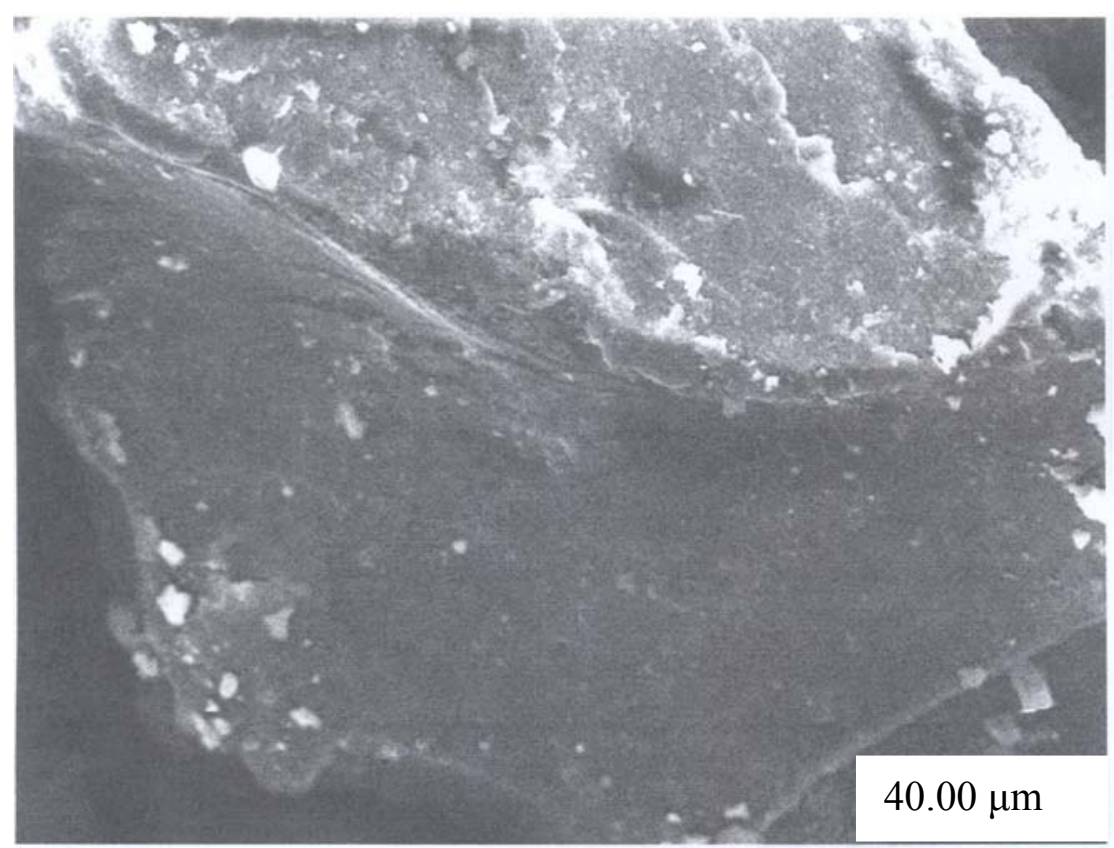

Fig.8- SEM micrograph of $\mathrm{HNO}_{3}$ leached residual coal 


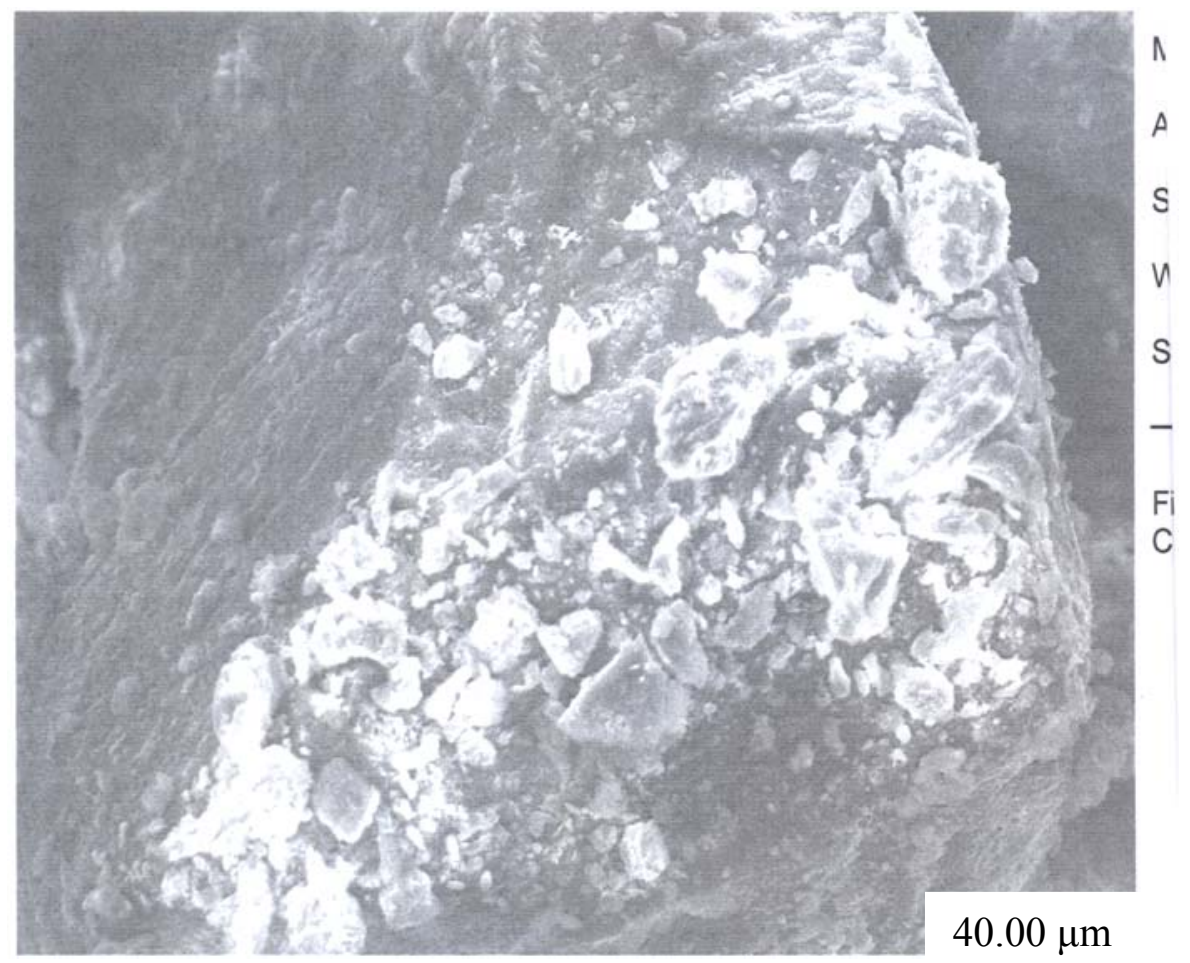

Fig. 9- SEM micrograph of $\mathrm{CH}_{3} \mathrm{COONH}_{4}$ leached residual coal

Some coal mineral matter may be discrete, organically bound and trace. An attempt was made to remove organically bound elements as well. The sample understudy was leached with ammonium acetate as leachant. The residual coal was studied by SEM. The corresponding micrograph is displayed in Fig. 8. One can see surface disintegration in the form of generation of micro fissures, cracks, crevices, kerfs, protrusions and valleys which indicate the possibility of the removal of organically bound elements.

\section{CONCLUSION}

It can be concluded from the results that amongst the lea chants employed, EDTA and acid mixture proved very effective for the removal of inorganic mineral phases. However, in the case of EDTA, prolonged or extended leaching time is suggested.

Acknowledgements: The authors are grateful to Mr Mohammad Umar, and Khalid Shah , Centralized Resource Laboratory, Department of Physics, University of Peshawar, N.W.F.P Pakistan .

\section{REFRENCES}

1. Hüttinger, K.J., and Krauss, W., 1981. Catalytic activity of coal minerals in hydrogasification of coal. Fuel, Vol.60, pp. 93-102. 
2. Montano, P.A., Bommannavar, A.S., and Shah, V., 1981. Mössbauer study of transformations of pyrite under conditions of coal liquefaction. Fuel, Vol.60 , pp.703711.

3. Tomita, A., Higashiyama, K, and Tamai, Y., 1981. Scanning electron microscopic study on the catalytic gasification of coal. Fuel, Vol.60, pp. 103-114.

4. Mukherjee, S., Mahiuddin, S., Bprthakur, P., 2001. Demineralization and Desulfurizatipn of Subbituminous Coal with Hydrogen Peroxide. Energy Fuel, Vol.15 No.6, pp. 1418-1424.

5. Karaca, H., Onal, Y., 2003. Demineralisation of Lignites by Single and Successive Pretreatment. Fuel, Vol.82, No.12, pp.1517-1522.

6. Erol, M., Colduroglu, C., Aktas, Z., 2003. The Effect of Reagents and Reagent Mixtures on Froth Flotation of Coal Fines, Int J Miner Process, Vol.71, No.1-4, pp.131145.

7. Polat, M., Polat, H., Chander, S., 2003. Physical and Çhemical İnteractions in Coal Flotation. Int J Miner Process, Vol. 72, No.1-4, pp.199-213.

8. Tao, D., Li, B., Johnson, S., 2002. A Flotation Study of Refuse Pond Coal Slurry. Fuel Process Technol, Vol.76, No.3, pp.201-210.

9. Nugteren, H.W., Janssen-Jurkovícová, M.., Scarlett, B., 2002. Removal of heavy metals from fly ash and the impact on its quality. Journal of Chemical Technology \& Biotechnology, Vol. 77, pp.389-395.

10. Akers, D J., 1998. Major Changes in US Coal Prep. World Coal, Vol.7, pp.45- 49.

11. Kazonich, G., and Kim, A.G., 1997. Leaching Fly Ash with Environmental and Extractive Lixiviants, 12th International Symposium on Coal Combustion By-Product Management and Use, American Coal Ash Assoc., Orlando, FL, 11-18.

12. Kumar, M., Shankar, R.H., 2000. Removal of Ash from Indian Assam Coking Coal Using Sodium Hydroxide and Acid Solutions. Energy Sources, 22, pp.187-196.

13. Lastra, R., Petruk, W., Wilson, J.,1998. Image analysis techniques and applications to mineral processing. In: Modern approaches to ore and environmental mineralogy. Mineralogical Association of Canada. Short Course Series, 27, 327-366. 
14. Gabas, S.G., Análise de Imagens Aplicada à Caracterização de Minérios - Análise Modal e Liberação. Dissertação de Mestrado, Escola Politécnica da Universidade deSão Paulo, 1999.

15. Kahn, H., Sant'Agostino, L., Mano, E.S., Tassinari, M.M., 1998. Acta Microscopica.7-A, pp.241-244.

16. Fruehan, R J., Li, Y., Brabie, L., 2003. .Dissolution of magnesite and dolomite in simulated EAF slags. Iron \& Steel Society International Technology Conference and Exposition, Indianapolis, IN; USA; 27-30, pp.799-812.

17. Romero, M and Rincón., J.M., 1999. Surface and bulk crystallization of glass-ceramic in the $\mathrm{Na}_{2} \mathrm{O}-\mathrm{CaO}-\mathrm{ZnO}-\mathrm{PbO}-\mathrm{Fe}_{2} \mathrm{O}_{3}-\mathrm{Al}_{2} \mathrm{O}_{3}-\mathrm{SiO}_{2}$ system derived from a Goethite waste. Journal of the American Ceramic Society, Vol. 82, p.1313.

18. Petruk, W., 2002. Imaging of minerals, ores and related products to determine mineral characteristics. Minerals and Metallurgical Processing, Vol.19, pp.50-56.

19. Petruk, W., 1998. Image analysis for mineral beneficiation. J. Met. Vol.40, pp.29-31.

20. Belkin, H. E., Zheng, B., and Finkelman, R. B., 1997. Fourth International Symposium on Environmental Geochemistry (U.S. Geological Survey, Reston, VA), U.S. Geological Survey Open-File Report, 97-496, 10.

21. Belkin, H. E., Zheng, B., Zhou, D., and Finkelman, R. B., 1997. Fourteenth Annual International Pittsburgh Coal Conference, CD-ROM (University of Pittsburgh).

22. Belkin, H. E., Warwick, P., Zheng, B., Zhou, D., and Finkelman, R. B., 1998. Fifteenth Annual International Pittsburgh Coal Conference, CD-ROM (University of Pittsburgh).

23. Khan,M.A., Ahmad, I., M. Tariq Jan, M.T., and Karim, I., 2002. Mineral mater identification in some Pakistani coals. Fuel Processing Technology, Vol.75, pp.1-8. 24. Landtwing, M.R., and Pettke, T., 2005. Relationships between SEMcathodoluminescence response and trace-element composition of hydrothermal vein quartz. American Mineralogist, Vol.90, pp.122-131.

25. Mukherjee, S., Borthakur, P., 2004. Demineralization of Sub-bituminous High Sulphur Coal Using Mineral Acids. Fuel Process Technol., Vol. 85, No.2-3, pp.157-164. 
26. Gülen, J., Doymaz, İ., Pişkin, M., Ongen, S., Pişkin, S., 2003. Leaching of Nallıhan Lignites with some acid. Proceedings of the X. Balkan Mineral Processing Congress, Varna, Bulgaria. 